УДК

\title{
ОПТИМИЗАЦИЯ МЕТОДОМ ПЧЕЛИНОГО РОЯ ПРОФИЛИРОВАННОГО ЩЕЛЕВОГО ИЗЛУЧАТЕЛЯ ШИРОКОПОЛОСНОЙ СКАНИРУЮЩЕЙ Е-ПЛОСКОСТНОЙ РЕШЕТКИ
}

\author{
ВАСИЛЕНКО Д. О., МАРТЫНЮК С. Е. \\ Национальный технический университет Украины \\ «Киевский политехнический институт», \\ Украина, Киев, 03056, пр-т Победь 37
}

\begin{abstract}
Аннотация. Приведена новая методика оптимизации одностороннего профилированного щелевого излучателя (ПЩИ) как элемента широкополосной Е-плоскостной линейной антенной решетки. Форма щелевого профиля антенны математически представлена в виде кусочно-линейной функции. Метод многопараметрической оптимизации «пчелиного роя» применен для нахождения координат кусочно-линейной функции профиля антенны для минимизации уровня активных отражений ПЩИ в составе сканирующей решетки. Показана теоретическая возможность снижения уровня активных отражений ПЩИ до -15 дБ в условиях работы в составе Е-плоскостной линейной антенной решетки в полосе частот 5-10 ГГц и секторе углов сканирования $\pm 30^{\circ}$. Предложенный подход проектирования решеток проверен на практике путем экспериментальных исследований двух изготовленных образцов линейных антенных решеток с фиксированными значениями отклонения направления главного лепестка диаграммы направленности на $0^{\circ}$ и $30^{\circ}$ соответственно. Каждый из тестовых образцов решеток состоит из 8 одинаковых ПЩИ с оптимизированным кусочно-линейным законом профиля излучающих щелей. Решетки возбуждаются посредством 8-канальных микрополосковых делителей мощности параллельного типа с соответствующими микрополосковыми линиями задержки на выходах, которые обеспечивают необходимые фазовые распределения на ПЩИ в широкой полосе частот
\end{abstract}

Ключевые слова: антенная решетка; метод пчелиного роя; профилированный щелевой излучатель; антенна Вивальди

\section{1. ВВЕДЕНИЕ}

Профилированные щелевые излучатели (ПЩИ) относятся к наиболее перспективным техническим решениям проблемы создания широкополосных сканирующих фазированных антенных решеток в широком секторе углов. Оригинальная конфигурация ПЩИ (предложенная Гибсоном антенна Вивальди в [1]) предполагает использование фольгированной медью с обоих сторон диэлектрической подложки, обладающей малыми потерями на СВЧ. Классическая конструкция ПЩИ содер- жит излучающую щель с экспоненциальным профилем и ортогонально ориентированную возбуждающую микрополосковую линию с радиальным шлейфом на конце, вытравленные в металле на противоположных сторонах подложки. Описанная геометрия позволяет получить удовлетворительные характеристики согласования одиночной ПЩИ не только в случае использования экспоненциального закона расширения профиля щели, но также при линейном [2], параболическом [3], постоянном и др. законах, если ширина и длина антенны пре- 